\title{
COMUNIDADES DE APRENDIZAGEM DOCENTE: 0 DESAFIO DA FORMAÇÃO DE PROFESSORES PARA O PROEJA
}

COMMUNITIES OF TEACHING LEARNING: THE CHALLENGE OF TEACHER TRAINING FOR PROEJA

\section{COMUNIDADES DE APRENDIZAJE DOCENTE: EL DESAFÍO DE LA FORMACIÓN DE PROFESORES PARA EL PROEJA}

\author{
Rozana Quintanilha \\ Gomes Souza* \\ Gerson Tavares do \\ Carmo* *
}

* Doutoranda e Mestre em Cognição e Linguagem pela Universidade Estadual do Norte Fluminense Darcy Ribeiro (UENF). Licenciada em Letras - Língua Portuguesa e Literatura Brasileira pelo Centro Universitário Fluminense e Especialista em Língua Portuguesa pela Universidade Salgado de Oliveira (Universo). Atualmente, é professora do Instituto Federal de Educação, Ciência e Tecnologia Fluminense (IFF). Tem experiência nas áreas de Letras e Educação, com ênfase em Língua Portuguesa e Educação de Jovens e Adultos. Integrante do grupo de pesquisa Núcleo de Estudos sobre Acesso e Permanência na Educação (IFF/UENF). Campos dos Goytacazes, Rio de Janeiro, Brasil. E-mail: rozanaquintanilhags@gmail.com

**Professor associado da UENF. Pós-doutorado em Sociologia Pragmática pela Universidade Nova de Lisboa. Doutorado em Sociologia Política e Mestrado em Cognição e Linguagem, ambos na UENF. Líder do Grupo de Pesquisa Escrita: Poder e Subjetividades (UENF) e Vice-líder do Núcleo de Estudos sobre Acesso e Permanência na Educação (IFF/ UENF). Cordeiro, Rio de Janeiro, Brasil. E-mail: gtavares33@gmail.com

Recebido para publicação em: 10.8.2018

Aprovado em: 21.5.2019

\section{Resumo}

As Comunidades de Aprendizagem Docente e a Educação Profissional integrada à Educação Básica na modalidade de Jovens e Adultos são o objeto de estudo deste artigo. Tendo em vista a formação docente, que implica uma mudança de paradigma frente à nova configuração escolar da sociedade contemporânea, o texto traz reflexões sobre uma questão eminente nas demandas da educação: o desenvolvimento de uma cultura de formação docente permanente e colaborativa em prol da educação de jovens e adultos.

Palavras-chave: Comunidades de aprendizagem docente. Permanência docente. Proeja.

\section{Abstract}

Communities of Teaching Learning and the Vocational Education integrated to Basic Education in the Young and Adult type is the study object of this article. In view of teacher training, which implies a paradigm shift in the face of the new school configuration of contemporary society, the text reflects on an eminent issue in education demands: the development of a culture of permanent and collaborative teacher training for young and adults education.

Keywords: Communities of teaching-learning. Teaching permanence. Proeja. 


\section{Resumen}

Las Comunidades de Aprendizaje Docente y la Formación Profesional integrada a la Educación Básica en la modalidad de Jóvenes y Adultos es el objeto de estudio de este artículo. Teniendo en vista la formación docente, que implica un cambio de paradigma frente a la nueva configuración escolar de la sociedad contemporánea, el texto presenta reflexiones sobre una cuestión eminente en las demandas de la educación: el desarrollo de una cultura de formación docente permanente y colaborativa en pro de la educación de jóvenes y adultos.

Palabras clave: Comunidades de aprendizaje docente. Permanencia docente. Proeja.

\section{Introdução}

Atualmente, a docência atravessa uma crise, pois o professor passou a ter novas atribuições e responsabilidades que o tornam uma figura contraditória. Sua ação ganhou um novo enfoque, que é atender a um novo aluno, mas atuando em um mesmo modelo tradicional de escola.

Esse quadro de tensões e contradições, oriundas do processo de evolução histórica da profissão docente, ganha maior complexidade quando o foco das análises são os professores que atuam na modalidade de jovens e adultos. Sem uma formação específica para atender ao público do Programa Nacional de Integração da Educação Profissional com a Educação Básica na Modalidade de Educação de Jovens e Adultos (Proeja) ${ }^{1}$, esses professores sofrem por não terem, na escola, um espaço propício e acolhedor à troca de experiências. Na solidão, muitas vezes alimentada pela competitividade entre os pares, mantêm-se nas práticas tradicionais e burocráticas e se fecham para a reflexão partilhada.

Contextualizar a solidão é transitar entre conceitos como desagregação, desmembramento, individualismo, frustração, desânimo, angústia, ausência, narcisismo e prepotência. Os sentidos de "solidão" são modificados conforme as mudanças subjetivas de cada época ${ }^{2}$, ora assumindo um caráter positivo, ora negativo. Contudo, a solidão é inerente ao ser humano.

Já a solidão que se apresenta na docência atual está diretamente relacionada à fragmentação do conhecimento em disciplinas. Pois, desse modo, a escola promove um processo de apropriação e de propriedade do conteúdo ministrado, e não de interação. Assim, pode-se apontar a solidão docente como causa de mal-estar no mundo contemporâneo. Percebe-se em muitos professores o desconforto, o desânimo, a angústia, a revolta, a acomodação e a baixa autoestima. Entretanto, há aqueles que buscam estratégias para escapar do "fechar-se em si", e então se abrir para a integração. 
Pensando nisso, este artigo, por meio de uma revisão de literatura, procura discutir o trabalho profissional dos professores que atuam no Proeja, dando ênfase às Comunidades de Aprendizagem Docente como estratégia de formação permanente do professor. Tal proposta preconiza a expansão da escola como espaço público democrático, participativo, visando profundas mudanças na pedagogia e na organização escolar, "uma vez que a afirmação social da profissão docente depende da qualidade do trabalho interno nas escolas" (NÓVOA; VIEIRA, 2017). Pleiteia-se, assim, um novo contrato social em torno da educação, pautado em uma comunidade de pertencimento que une, identifica, partilha e respeita as individualidades.

\section{A docência no Proeja}

A implementação do Proeja nos Institutos Federais de Educação, estipulada pelo Decreto n. 5.478/2005, tornou emergente a discussão em torno do atendimento a esse público diferenciado, que possui um estigma cristalizado historicamente. As ações propositivas em prol desses alunos exigem que os docentes façam mais do que simplesmente mexer nas margens da prática educacional. É preciso superar o estigma sustentado por uma voz do senso comum, a qual ecoa uma subjetividade discursiva que desqualifica esses alunos por julgar irrecuperável o tempo em que eles deixaram de frequentar a escola, como se o sistema os tivesse descartado com razão.

É preciso

superar 0

estigma

sustentado por

uma voz do

senso comum
O docente sofre os impactos de uma sociedade contemporânea que convive com a contradição de atender um tipo de alunado que não combina com o modelo de aluno ideal, constituído a partir dos padrões que foram determinados e legitimados pela sociedade. De acordo com Fiss (2016, p. 121), "os professores, pelo menos em parte, relatam grandes dificuldades em permanecer/estar em sala de aula, apontando a existência de impasses nas relações com os estudantes e suas culturas".

Cumpre destacar que o modo como os professores lidam com a complexidade da docência para permanecer na modalidade de jovens e adultos torna-se um enigma, e na tentativa de explicá-lo, deve-se levar em conta o histórico social e profissional desses docentes ao longo dos tempos, assim como as demandas atuais da sociedade.

Essas observações suscitam reflexões sobre a profissão docente em si, a qualidade do ambiente escolar, a autonomia do professor, a formação inicial e continuada, a permanência docente e as tensões em torno da modalidade de jovens e adultos. Nesse ínterim, surgem no ambiente escolar formas de regulação, homogeneização e controle da profissão docente, por meio de dispositivos burocráticos e avaliativos impulsionados por programas pautados na meritocracia, mas que pouco atingem a raiz da questão.

Afınal, não existindo uma formação específıca para atender a um público diferenciado como o do Proeja, como o docente, no seu exercício profissional, busca so- 
lucionar os problemas que surgem no cotidiano escolar? Como assegurar o desenvolvimento profissional permanente do professor em um ambiente escolar que não fertiliza a autonomia, a reflexão, a colaboração, e sobretudo, não potencializa a escola como espaço aprendente?

A consciência dessa realidade de desvalorização profissional impulsiona a busca por uma coerência na forma como se concebem os programas de formação (TARDIF, 2014b). Nesse sentido, pode-se inferir que a formação docente, tal qual vem sendo concebida ao longo dos últimos tempos, precisa ser repensada.

A necessidade de se estabelecer uma cultura de formação docente permanente aponta para a emergência de Comunidades de Aprendizagem, as quais provocam uma mudança de paradigma sobre a formação docente: a cultura do trabaIho individualista passa a ser substituída pelo trabalho colaborativo. Enquanto o individualismo profissional é embutido de isolamento, característico da escola tradicional, em que as aulas são dadas a portas fechadas, com as carteiras separadas e os professores preparando seus planos de ensino sozinhos, o colaborativo é pautado no trabalho em equipe, corresponsabilizando os resultados, discutindo coletivamente as soluções para os conflitos surgidos no cotidiano escolar (DAY, 2003).

Constata-se que o perfil do professor contemporâneo, fruto do modelo arcaico de escola, insiste em vigorar e resistir em pleno século 21, mesmo sem atender a esse novo público de jovens e adultos. Ao mesmo tempo, manifesta-se a angústia de muitos professores em perceber que suas práticas pedagógicas não dão conta da diversidade desses alunos. Em suma, o momento atual é de transição na educação, o que Roldão (2000) denomina de mudança de "paradigma vigente" para o "paradigma emergente". As transformações ocorridas na sociedade apontam em direção à desburocratização na educação, mas, culturalmente, fica enraizado o modelo tradicional de escola e de formação profissional.

A estrutura escolar marca e define o trabalho docente, ou seja, o contexto escolar encarna o trabalho docente ao mesmo tempo em que o reproduz. Portanto, não há como buscar uma mudança na formação docente sem mudar as normas de organização da escola. Sobre isso, Nóvoa (2001, p. 23) explica que a continuidade do aprendizado é essencial à profissão do professor, e que é preciso superar uma lógica que separa os diferentes tempos de formação - privilegiando a inicial - para outra que percebe esse desenvolvimento como processo.

Diferentemente de profissões que se desenvolveram coletivamente, a profissão docente seguiu uma perspectiva individualista, apesar de envolver a coletividade na organização escolar. Relativamente à natureza do trabalho profissional docente, Nóvoa (2001) esclarece que a dinâmica interna individual da docência se dá dentro de uma dinâmica organizacional coletiva, mas não em uma dimensão coletiva, ou melhor, os professores não reconhecem a necessidade de legitimar a coletividade profissional como potencial desse grupo. 
Ainda segundo Nóvoa (2001, p. 13), a contradição consiste em que novas práticas de ensino só nascem com a recusa do individualismo, mas, historicamente, os docentes desenvolveram identidades isoladas. Falta a afirmação de um coletivo profissional que rejeite o corporativismo. Falta a formação de equipes de trabalho reflexivas e a participação nos planos de regulação, de pesquisa, de avaliação conjunta e formação continuada. Mais ainda, são cada vez mais necessários movimentos pedagógicos que aglutinem profissionais de origens diversas em torno de um mesmo programa para a renovação do ensino.

Falta a

afirmação de

um coletivo

profissional

que rejeite 0

corporativismo
Para Tardif (2014a, p. 115), esse olhar de que o trabalho realizado na escola, na verdade, envolve diversas categorias de agentes é um fator que comumente é negligenciado no planejamento educacional.

Sendo assim, como propor um trabalho docente coletivo se a própria organização das atividades nas escolas, conforme se dá, não tem esse objetivo, nem mesmo facilita a construção de um trabalho com esse propósito? Há o aspecto individual, mas há também um diálogo com os colegas, que deve ser construído mutuamente para o fortalecimento e renovação da profissão.

\section{Comunidades de aprendizagem docente}

A investigação aqui proposta destaca o envolvimento das Comunidades de Aprendizagem Docente como motivação para o desenvolvimento profissional do professor. Autores como Nóvoa (2001, 2009, 2017), Alarcão (2001; ALARCÃO; TAVARES, 2003), Roldão (2000, 2005, 2007), Orland-Barak (2012), Wald \& Castleberry (2000) as designam de Comunidades Profissionais de Aprendizagem.

Tais Comunidades surgem, frequentemente, como termo sinônimo de Comunidades de Prática, embora as Comunidades Profissionais de Aprendizagem sejam oriundas dos desdobramentos das Comunidades de Prática, as quais se fundamentam na Teoria Social da Aprendizagem, desenvolvida por Wenger (2001). De acordo com esse autor, há quatro dimensões essenciais interligadas para caracterizar a participação social na aprendizagem:

i. significado - disposição e capacidade de mudança, seja individual, seja coletiva, para uma recomposição investigativa e pedagógica;

ii. prática - composição pedagógica que consolide o compromisso e o empenho conjunto da comunidade a fim de promover o desenvolvimento profissional;

iii. comunidade - pertencimento a um grupo de pessoas dentro de uma configuração social que possibilita a iniciativa, a interação e o reconhecimento de competências;

iv. identidade - predisposição para aprender e transformar.

Wenger (2001) ainda esclarece que a Comunidade de Prática pode ser denominada também de Comunidade de Ação ou Comunidade de Interesse, e que ela não é es- 
pecífica de um grupo, ao contrário, todos pertencem a uma Comunidade de Prática. Afınal, é próprio do ser humano estar sempre em um processo de aprendizagem pelo qual se interage com o mundo, com os outros e com os grupos do qual se faz parte, como família, igreja, trabalho e outros. Entretanto, essa interação não torna as pessoas iguais, nem é esse o seu objetivo, pois cada um é um ser único, com interesses e perspectivas diferentes. Nesse sentido, cada um faz escolhas sobre aquilo que importa, negociando significados, assumindo posturas e exposições públicas a partir das vivências.

O mesmo autor complementa elucidando que os significados são construídos a partir das experiências e que o consenso desses pressupõe a interação de dois processos: participação e reificação. Por participação o autor compreende que é um processo que interfere na identidade de cada indivíduo, uma vez que ocorre uma transformação na pessoa; por reificação, entende que essa experiência solidificada implica processos como fazer, inferir, descrever, compreender e reestruturar, sendo dois processos que se complementam.

Nas palavras de Meirinhos e Osório (2014), as Comunidades de Prática apresentam semelhanças com as Comunidades de Aprendizagem, já que se referem a pessoas que se implicam ativamente em processos colaborativos de resolução de problemas, apoiando-se na experiência e no conhecimento simultaneamente partilhado e distribuído entre os membros da comunidade.

Assim, a Comunidade de Aprendizagem Docente é concebida como processo em que os indivíduos, por meio da partilha dentro de uma organização, e, sobretudo, pela consciência da necessidade de trocarem experiências com seus pares, desenvolvem conhecimentos no âmbito profissional. Desse modo, o grau de envolvimento e pertencimento dos professores com a prática da comunidade é determinante para assegurar o desenvolvimento profissional (ROLDÃO, 2007).

Na opinião de Wald e Castleberry (2000), o desenvolvimento profissional do professor pressupõe disposição, diligência, empreendimento, mas também risco perante as dificuldades e os conflitos que surgem na sua prática. Para enfrentar os riscos e as inseguranças, parece pertinente o trabalho do professor em colaboração com seus pares, de entreajuda e apoio, que permite dar sentido ao diálogo profissional das Comunidades de Aprendizagem Docente.

De acordo com Roberts e Pruitt (2010), os professores assumem cinco dimensões em uma Comunidade de Aprendizagem Docente:

i. colegas, por instalarem um diálogo entre pares;

ii. líderes, por se responsabilizarem pelas decisões e ações tomadas;

iii. aprendentes, por atribuírem valor não ao ensino, mas à aprendizagem;

iv. pedagogos, por discutirem estratégias pedagógicas;

v. integradores, por envolver os pais dos alunos nas inovações pedagógicas. 
Nessa ótica, as Comunidades de Aprendizagem Docente englobam novas formas de se compreender e pensar a prática educativa, a qual une experiência, reflexão, confronto de ideias, ação e formação pela investigação. Aliados, esses fatores atribuem ao saber dos professores um caráter mais práxico do que prático (ALARCÃO; TAVARES, 2003, p. 44).

Nóvoa (2017) alerta para o fato de que o desenvolvimento profissional, por si só, não dá conta do sucesso das Comunidades nem mesmo da melhoria da qualidade na educação. É preciso que o grupo também se conscientize da importância de ajudar e ser ajudado, e, sobretudo, um investimento no estímulo ao pensar, refletir, partilhar e desenvolver uma compreensão mútua sobre os problemas e soluções.

Alarcão (2001, p. 25) aponta para a necessidade de se conceber a escola como espaço aprendente, como organização que pensa sobre si própria na sua missão social e na sua estrutura, confrontando-se com o desenvolvimento da sua atividade em um processo heurístico ao mesmo tempo avaliativo e formativo.

Nesse enquadramento, Roldão (2007) reforça a ideia de que os professores, integrados em uma Comunidade de Aprendizagem Docente, transformam a escola, aprendem na reflexão partilhada e desenvolvem competências de autorregulação, repercutindo tanto no seu desempenho profissional quanto no melhor desempenho dos alunos.

O exposto no paradigma emergente parece relacionar-se com pressupostos das escolas concebidas como Comunidades de Aprendizagem Docente, dado que a escola deixa de delegar e passa a refletir com autonomia; deixa de lamentar o insucesso e passa a desconstruir paradigmas; deixa de cumprir regras e passa a criá-las (ROLDÃO, 2000).

O papel do professor ganha destaque em um contexto de trabalho colaborativo, investigativo e reflexivo sobre sua prática. Como afirma Roldão (2005, p. 17), o poder de decisão do professor sobre suas atividades ultrapassa a anterior posição de apenas executor das decisões dos outros, graças a uma forma muito mais interativa de se integrar a uma instituição escolar.

papel do professor ganha destaque em um contexto de trabalho colaborativo
Para Nóvoa (2009), o desenvolvimento profissional em uma Comunidade de Aprendizagem Profissional começa com uma concepção investigativa e ativa por parte de todos os elementos que dela fizerem parte, considerando um aspecto fundamental da aprendizagem docente, a construção do conhecimento profissional e a correlação teoria-prática.

Em suma, com vistas ao "paradigma emergente" na educação, não há como negar que existe um consenso quanto ao anseio por transformações na escola, no que tange à necessidade de a estrutura organizacional ser mais aberta, dinâmica, aprendente e reflexiva; e, quanto ao trabalho do professor, que lhe seja permitido atuar de forma mais inovadora, reflexiva, ativa e investigativa com o intuito de promover o sucesso que advém da melhoria da qualidade de educação. 


\section{Considerações finais}

Conforme se viu ao longo deste artigo, complexas são as questões inerentes ao desafio atual da formação continuada de professores para o Proeja. A título de síntese, compreendeu-se que o exercício da docência, tal como se concebe atualmente, é produto de uma evolução histórica que traduz os conflitos e desencontros no ambiente escolar. A docência vem evidenciando, ao longo dos séculos, uma estrutura sobre a qual se vê, lentamente, a ânsia por uma nova e coletiva dinâmica profissional, que requer desnudá-la, a fim de demonstrar como essa intervém na aprendizagem e em que condições ela se sustenta.

Assim, a docência, nessa configuração social contemporânea, tanto em formação inicial quanto em formação permanente, deve ser receptiva à mudança de paradigmas, rompendo com tradições e culturas que não contemplem a diversidade do público jovem e adulto.

No entanto, as reflexões aqui destacadas apontam que, apesar de a docência requerer um contrato inovador, que respeite a especificidade e a diversidade do público jovem e adulto, o fazer e o pensar docente histórico e estruturalmente construído ainda reflete, contraditoriamente, um desejo de padronização e homogeneização da educação, o que é característico da situação de transição, uma vez que novas e velhas concepções convivem para daí surgir um novo pensamento.

Por fim, sintetizar uma proposta de intervenção sobre as Comunidades de Aprendizagem Docente para o desenvolvimento profissional do professor significa estabelecer a escola como espaço aprendente e autoformativo, e contribuir para as discussões que requerem a transformação e a intervenção na educação profissional integrada à educação básica na modalidade de jovens e adultos.

\section{Notas}

1 O Proeja foi criado para oferecer, além do ensino médio, uma qualificação profissional em nível técnico para os jovens e adultos que estavam afastados dos bancos escolares. Mais recentemente, um novo termo - Educação Profissional e Tecnológica/Educação de Jovens e Adultos (EPT/EJA) - vem sendo introduzido, com uma proposta de itinerários formativos.

${ }^{2}$ Na Idade Antiga, a solidão era associada a determinações espaciais, como lugares para se cumprir o exílio. Na Idade Média, a solidão era confundida com a loucura, pois os loucos eram considerados solitários, e para tratá-los, era preciso socializá-los. No mundo moderno e tecnológico, as pessoas têm desfrutado da solidão como forma de autoconhecimento, de encontrar equilíbrio emocional, paz e harmonia. 0 encontro consigo mesmo pode significar um diálogo interno que contribua para aumentar a autoconfiança e a autonomia, pois para se estabelecer parcerias bem-estruturadas é preciso encontrar-se consigo mesmo e vencer a solidão. Entendendo a solidão como questão que marca o sujeito contemporâneo, ela transcende a diferença de estar só e sentir-se só, sendo possível estar só entre muita gente. 


\section{Referências}

ALARCÃO, Isabel. Escola reflexiva e nova racionalidade. Porto Alegre: Artmed, 2001.

ALARCÃO, Isabel; TAVARES, José. Supervisão pedagógica: uma perspectiva de desenvolvimento e aprendizagem. 2. ed. Coimbra: Almedina, 2003.

BRASIL. Decreto n. 5.478, de 24 de junho de 2005. Institui, no âmbito das instituições federais de educação tecnológica, o Programa de Integração da Educação Profissional ao Ensino Médio na Modalidade de Educação de Jovens e Adultos - Proeja, e dá outras providências. Brasília, DF: Presidência da República, Casa Civil, 2005. Revogado pelo Decreto n 5.840, de 2006. Disponível em: https://www.planalto.gov.br/ccivil_03/_ato2004-2006/2005/Decreto/D5478.htm. Acesso em: 10 jul. 2016.

DAY, Christofher. Desenvolvimento profissional de professores: os desafios da aprendizagem permanente. Porto: Porto Editora, 2003.

FISS, Dóris Maria Luzzardi. O serา/estar professor na escola: permanência e negociações. In: CARMO, Gerson Tavares do (org.). Sentidos da permanência na educação: o anúncio de uma construção coletiva. 1. ed. Rio de Janeiro: Tempo Brasileiro, 2016.

MEIRINHOS, Manuel; OSÓRIO Antônio. A colaboração em ambientes virtuais: aprender e formar no século XXI. Braga: Associação ArcaComum, 2014.

NÓVOA, Antonio. Antonio Nóvoa: professor se forma na escola. [Entrevista cedida a] Paola Gentile. Nova Escola, São Paulo, n. 142, 1 maio 2001. Disponível em: https://novaescola.org.br/conteudo/179/entrevista-formacao-antonio-novoa. Acesso em: 20 nov. 2017.

NÓVOA, António. Professores: imagens do futuro presente. Lisboa: Educa, 2009.

NÓVOA, António; VIEIRA, Pâmela. Um alfabeto da formação de professores.

Crítica Educativa, Sorocaba, v. 3, n. 2, p. 21-49, jan./jun. 2017.

ORLAND-BARAK, Lily. Construir a prática através da conversação em grupos de aprendizagem profissional: variações no tema. In: FLORES, M.; FERREIRA, F. (org.). Currículo e comunidades de aprendizagem: desafios e perspectivas. Santo Tirso: De Facto Editores, 2012. p. 97-119. 
ROBERTS, Sylvia M.; PRUITT, Eunice Z. Les communautés d apprentissage professionnelles. Québec: Chenelière Éducation, 2010.

ROLDÃO, Maria do Céu. Escola reflexiva e supervisão: uma escola em desenvolvimento e aprendizagem. In: ALARCÃO, Isabel (org.). A escola como instância de decisão curricular. Porto: Porto Editora, 2000.

ROLDÃO, Maria do Céu. Estudos práticos de gestão do currículo: que qualidade de ensino e de aprendizagem. In: ROLDÃO, Maria do Céu (coord.). Gerir o currículo é preciso: a questão da qualidade. Lisboa: Edição Universidade Católica Editora, 2005.

ROLDÃO, Maria do Céu. Função docente: natureza e construção do conhecimento profissional. Revista Brasileira de Educação, Rio de Janeiro, v. 12, n. 34, p. 94-181, jan./abr. 2007. Disponível em: http://www.scielo.br/pdf/rbedu/v12n34/a08v1234. pdf. Acesso em: 15 nov. 2017.

TARDIF, Maurice. Saberes docentes e formação profissional. 17. ed. Petrópolis: Vozes, 2014a.

TARDIF, Maurice. 0 trabalho docente: elementos para uma teoria da docência como profissão de interações humanas. 9. ed. Petrópolis: Vozes, 2014b.

WALD, Penelope; CASTLEBERRY, Michael (ed.). Educators as learners: creating a professional learning community in your school. Alexandria, VA: ASCD, 2000.

WENGER, Etiene. Comunidades de práctica: aprendizage, significado e identidad. 2. impr. Barcelona: Paidós, 2001. 